\title{
Computational Analysis of the Blade Loading on Tip Clearance Effects
}

\author{
Limin Wang, Yadong Liu*, Chengqin Li \\ ENN Energy Power Technology Co., Ltd., Shanghai, China \\ Email address: \\ wanglimin@enn.cn (Limin Wang), liuyadongd@enn.cn (Yadong Liu), lichengqin@enn.cn (Chengqin Li) \\ ${ }^{*}$ Corresponding author
}

\section{To cite this article:}

Limin Wang, Yadong Liu, Chengqin Li. Computational Analysis of the Blade Loading on Tip Clearance Effects. International Journal of Fluid Mechanics \& Thermal Sciences. Special Issue: Fluid Mechanics \& Thermal Sciences in Turbomachines.

Vol. 6, No. 4, 2020, pp. 95-107. doi: 10.11648/j.ijfmts.20200604.11

Received: June 27, 2020; Accepted: October 26, 2020; Published: November 16, 2020

\begin{abstract}
Gas turbines normally have the rotating and stationary parts. The rotational blades always need clearance to rotation. Blade tip clearance is one of the important parameters affecting performance, safety and stability of a gas turbine engine. However, it is difficult to measure the tip clearance accurately during the tests. The numerical studies are important methods to study the tip clearance effects. Tip clearance effects have been studied for a long time. However, there are still many aspects that are not fully understood and industries still don't have a good way to perform design with minimum tip clearance losses. In the gas turbine design, the tip clearance considerations are very critical for both performance and reliability. In this paper, we perform the numerical study on the tip clearance impacts during the aerodynamic design, especially the blade loading through blade counts. The study found that the proper blade loading could reduce the tip clearance sensitivity and reduce the tip clearance losses. In the cases of reasonable number of blades, the effect of clearance on the total pressure loss and efficiency had a linear relationship. But in the cases of small number of blades, the effect of clearance on the total pressure loss and efficiency is no longer linear. The study helped turbine designers to consider blade loading and tip clearance together during the turbine design.
\end{abstract}

Keywords: Gas Turbine, Blade Loading, Tip Clearance, Computational Fluid Dynamics (CFD)

\section{Introduction}

Gas turbines and aircraft engines need rotational turbo machines to produce the power. The compressor and turbine are the rotating components. The rotating blades need annular tip clearances between the rotor blade tips and the outer casing to allow the rotor blade rotating. This clearance, although mechanically necessary, is a source of the aerodynamic losses. The tip clearance is the tip gap between the shroud of the rotor blades and adjacent stationary casing wall. Due to the presence of pressure difference between the pressure and suction sides of the blade, there exists a leakage flow through the tip gap from blade pressure side to suction side. The pressure difference from upstream to downstream of the blades causes leakage flow to move from streamline direction in tip range. As an important parameter that affects the efficiency, stability and safety of the gas turbine engine, blade tip clearance, which is the radial distance between a rotor blade tip and the engine casing, has become the focus of researchers [1-18]. For a turbine, tip leakage losses constitute a major source of losses in turbine rotor blades, typically a clearance gap equal to 1 percent of the blade height is associated with a 1-3 percent penalty in stage efficiency without tip clearance flow control. The losses of performance due to tip clearance flow have been intensively studied for many years. However, many studies [1-18] were focused on the loss flow structure, loss magnitude and tip clearance flow controls. There are very limited studies reported that the blade loading affected the tip clearance losses.

As a rotating component, the power that a turbine can provide depends on the airflow flow through the area where the blade is located. The presence of the tip clearance causes a portion for the airflow to flow away without work and will damage the flow path, thereby, affecting the efficiency of the turbine [1-18]. With further studies, researchers explored the relationship between the tip clearance and the engine efficiency through experiments and numerical analysis. The larger the tip the lower the efficiency would be. Researchers 
found that when the tip clearance is increased, the efficiency of a turbine rotor decreases significantly. If the tip clearance is too big, it not only decreases the efficiency of the engine but also consumes more fuel and impacts the turbine cooling. On the contrary, the decrease in tip clearance can reduce the working medium leakage and the loss of the end wall, so as to improve the gas turbine performance. However, since the tip clearance is small and the gas turbine power systems work in environments of high temperature, high pressure and large vibration, these factors cause the changes in tip clearance during operation, such as weather changes and power demand changes. Among them, temperature due to weather and fuel suppliers are the main factors. In addition, the friction between the fouling caused by corrosion and foreign objects, the change of the operating load of the turbine and the friction between the tip and the sealing strip caused by the transition state of the gas turbine will also lead to the changes in the tip clearance. Therefore, reducing the tip clearance needs to consider all these clearance changes.

The gap height can be a fraction of a millimeter but can have a disproportionately high influence on the stage efficiency. A large space between the blades and the outer casing results in detrimental leakages, while contact between them can damage the blades. Therefore, the evaluation of the performance degradation can help the turbine design and maintenance. In the design stage, tip clearance loss is the combination of the blade height, surface finish, manufacturing capability as well as the blade aerodynamic design. Therefore, the studies of these impacts are very critical for design. In this paper, the detailed studies of the blade loading influencing the tip clearance losses are conducted.

As part of the overall blade loss, the turbine tip clearance loss arises because at the blade tip the gas does not follow the intended path and therefore does not contribute to the turbine power output and interacts with the outer wall boundary layer. The decrease in turbine tip clearance may be a result of rubs during engine transients and the interaction between the blades and the outer casing. The reducing tip clearance needs to improve the manufacturing capability as well as a better tip clearance control system. These increase the turbine manufacturing cost. The aerodynamic designers always endeavor to minimize the clearance gap to improve the turbine performance without increasing the product cost. However, there are some limitations to reduce the clearance. At certain tip clearance, to design turbine rotating blades with small tip clearance losses is very interesting in the gas turbine industry. Previous studies on tip leakage flow were mainly based on a linear cascade and mainly focus on the tip flow structure [1-18]. In this study, an ENN newly developed turbine stage was studied. The new gas turbines always need higher performance and high reliability, which has brought great challenges to the development. This paper conducted the detailed analytical study for tip clearance loss impacts due to blade loading due to blade counts. This study will help to optimize the blade counts based on the tip clearance.

\section{Geometry Model and Calculations}

\subsection{Geometry Information}

The geometric model selected in this paper is the first stage of a three-stage axial flow turbine of an ENN newly developed 5MW gas turbine. The turbine flow path is shown as in figure 1 . The detailed geometry information of the turbine cascade is shown in table 1.

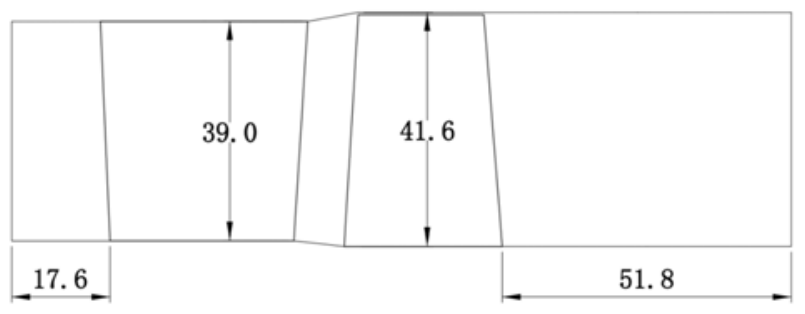

Figure 1. The turbine flow path.

Table 1. Geometry details.

\begin{tabular}{|c|c|c|c|c|c|c|c|}
\hline & & \multicolumn{3}{|c|}{ Stator } & \multicolumn{3}{|c|}{ Rotor } \\
\hline & & Hub & Midspan & Tip & Hub & Midspan & Tip \\
\hline Number of blades & $\mathrm{N}$ & & 30 & & & 58 & \\
\hline Chord & $\mathrm{C}$ & 62.07 & 67.00 & 72.17 & 35.00 & 35.00 & 35.00 \\
\hline Axial Chord & Cax & 32.93 & 35.00 & 37.13 & 28.30 & 25.52 & 22.52 \\
\hline Blade height & $\mathrm{h}$ & & 39 & & & 41 & \\
\hline Aspect ratio & $\mathrm{h} / \mathrm{C}$ & 0.63 & 0.58 & 0.54 & 1.17 & 1.17 & 1.17 \\
\hline Pitch/chord ratio & $\mathrm{S} / \mathrm{C}$ & 0.83 & 0.83 & 0.83 & 0.76 & 0.82 & 0.89 \\
\hline Solidity & $\mathrm{C} / \mathrm{S}$ & 1.20 & 1.20 & 1.21 & 1.32 & 1.22 & 1.13 \\
\hline Inlet Metal Angle & & -7.00 & -7.00 & -7.00 & 53 & 51 & 36 \\
\hline Outlet Metal Angle & & 78.97 & 78.97 & 78.97 & -74 & -74 & -74 \\
\hline Stagger angle & & 58.5 & 59 & 59.5 & 38.7 & 45.4 & 51.3 \\
\hline Shroud Diameter & $\mathrm{Dt}$ & & 570 & & & 573.2 & \\
\hline Hub/Tip Ratio & $\mathrm{Dh} / \mathrm{Dt}$ & & 0.863 & & & 0.855 & \\
\hline
\end{tabular}




\subsection{Calculation Details and Grid Independence Validation}

The NS solver with shear stress transport model turbulence model is used in this study. One of the most important calculation details for the turbulence models is the proper resolution of the boundary layer. The boundary layer resolution was considered by the dimensionless Y plus. It is used to check the location of the first node away from a wall. Automatic near-wall treatment was applied by $\mathrm{k}-\omega$ based shear stress model in CFX. The automatic near-wall treatment automatically switches from wall-functions to a low-Re near wall formulation as the mesh is refined i.e. wall function method was chosen at high $\mathrm{Y}+$ value and low-Re model was chosen at low $\mathrm{Y}+$ value. So the boundary layer was solved directly through the near wall fine mesh. To take advantage of the low-Re model, in this study we make sure that $\mathrm{Y}+$ is smaller than 1 .

The work fluid is a user defined combustion mixture. The compositions in this study are nitrogen, oxygen, carbon dioxide and vapor and their mass fraction are 0.76696 , $0.14958,0.04589$, and 0.03757 respectively. The dynamic viscosity and thermal conductivity are the function of the temperature through Sutherland's formula, i.e.

$$
\begin{gathered}
\frac{\mu}{\mu_{0}}=\frac{T_{r e f}+S}{T+S}\left(\frac{T}{T_{r e f}}\right)^{n} \\
\frac{\lambda}{\lambda_{0}}=\frac{T_{r e f}+S}{T+S}\left(\frac{T}{T_{r e f}}\right)^{n}
\end{gathered}
$$

Where $\mu_{0}=1.72 \times 10^{-5} \mathrm{~kg} /(\mathrm{m} * \mathrm{~s}), \mathrm{S}=194 \mathrm{~K}$, $\mathrm{T}_{\text {ref }}=273.15 \mathrm{~K}, \lambda_{0}=2.44 \times 10-2 \mathrm{~W} /(\mathrm{m} * \mathrm{~K}), \mathrm{n}=1.5$;

In this study, the first Stator was used to check the $\mathrm{Y}+$ value and mesh independence. The Stator run conditions are inlet total pressure of $1556.6 \mathrm{kPa}$, total temperature of $1480 \mathrm{~K}$, and inlet flow angle of zero degree. Turbulence Intensity at inlet is assumed at 5\% and outlet average static pressure is set to $985.9 \mathrm{kPa}$. The pressure Profile blend factor is 0.05 . The Stator blade hub and shroud surfaces are set as adiabatic and no slip. The simulations showed that the $\mathrm{Y}+$ value decreased from 17.1 to 0.9 when the first element offset decreased from $10 \mu \mathrm{m}$ to $0.5 \mu \mathrm{m}$. The figure 2 showed the relation between the first element offset near the wall and the blade wall $\mathrm{Y}+$ value. The result shows that when the near wall first element offset is $0.5 \mu \mathrm{m}$, the blade surface $\mathrm{Y}+$ value below 1. In current study, the near wall first element height $0.5 \mu \mathrm{m}$ can satisfy the requirements of the SST model for Y+ value.

Keeping the near wall first element offset is $0.5 \mu \mathrm{m}$, then increase the span elements and total elements, the span element numbers are $80,102,130$, the total element are about $1.16,1.64$ and 1.98 million; as illustrated in figure 4, the Stator inlet and outlet plane are named section 1 and 2. The Stator total pressure loss coefficient $\mathrm{K}_{\mathrm{N}}$ can be defined as follow:

$$
K_{N}=\frac{p_{01}-p_{02}}{p_{02}-p_{2}}
$$

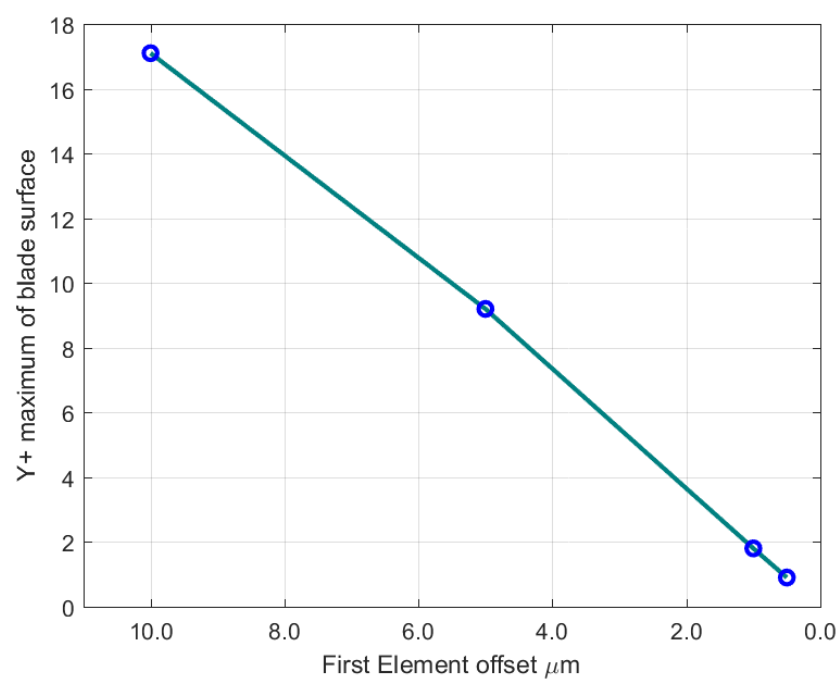

Figure 2. First Element offset and Y+ maximum of blade surface.

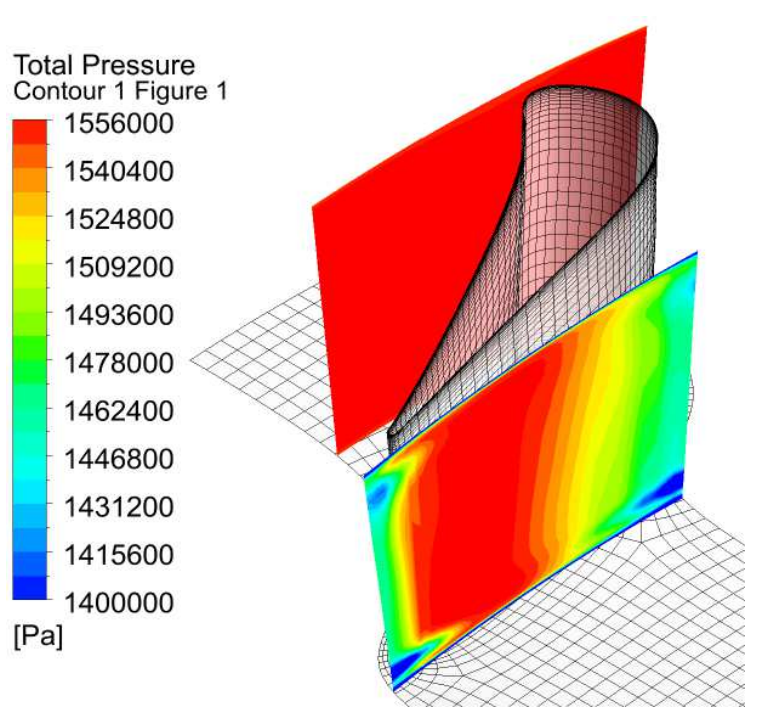

Figure 3. The inlet and outlet plane used to calculate $K N$.

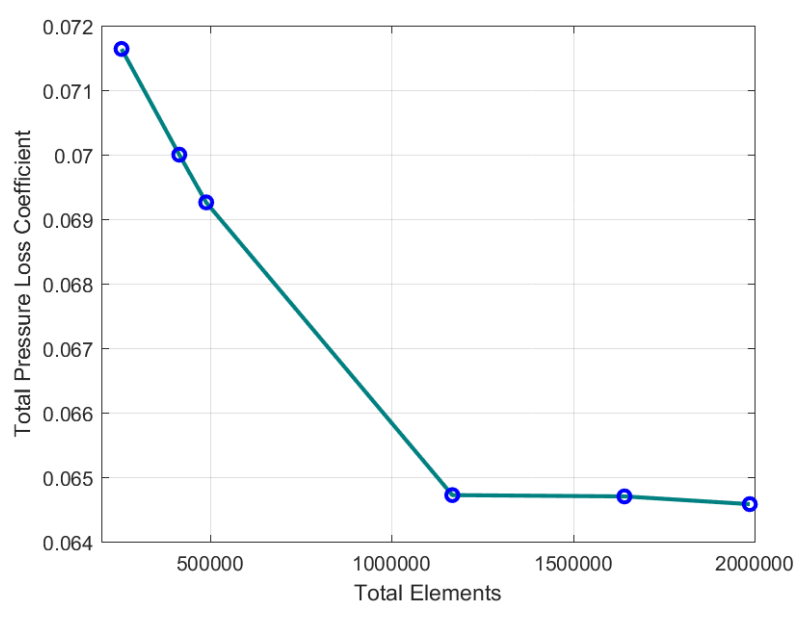

Figure 4. Total pressure loss coefficient results with different total elements. 
Here $p_{01}, p_{02}$ are the mass averaged total pressure of station 1 and 2 respectively. As shown in figure 5, the Stator total pressure loss coefficient gradually decreases as the increase of boundary layer resolution. But when the near wall first element offset keeps $0.5 \mu \mathrm{m}$ and the number of grids exceeds one million, the Stator total pressure loss coefficient has no significant difference. It can be seen that when mesh sizes larger than 1.5 million, the calculation demonstrates mesh independence.

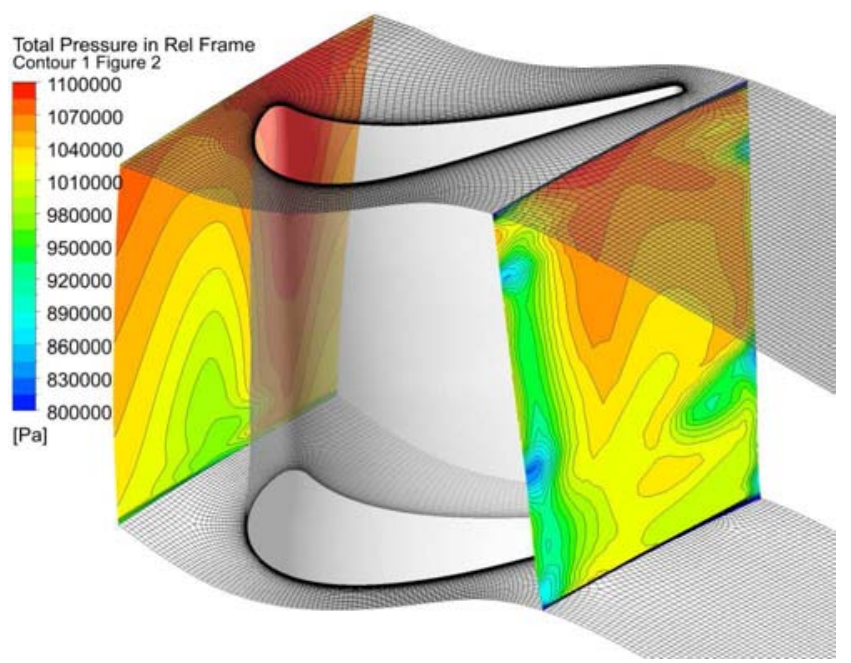

Figure 5. The Inlet and Outlet Location for Calculating the Rotor Row Total Pressure Loss Coefficient.

\section{Results and Discussion}

\subsection{The Effect of the Tip Clearance Size on Flow Performance}

The first stage of the turbine was studied. Six cases with different tip clearances and blade numbers were calculated by ANSYS-CFX 17.2. Table 2 summarized geometry details and the CFD calculated losses. For all calculations, the inlet boundary is the same as the single Stator row model. The rotor outlet pressure was set as $623.8 \mathrm{kPa}$. The rotational speed is $15350 \mathrm{rpm}$. As illustrated in Figure 5, two planes were chosen as rotor inlet and outlet station 2 and 3 . The number of blades in case $0 \mathrm{a}, 1 \mathrm{a}, 2 \mathrm{a}$ are all 58 and the tip clearance are $0.000 \mathrm{~mm}, 0.333 \mathrm{~mm}, 0.630 \mathrm{~mm}$ respectively. The number of blades in case $0 \mathrm{~b}, 1 \mathrm{~b}, 2 \mathrm{~b}$ are all 46 and the tip clearance are also $0.000 \mathrm{~mm}, 0.333 \mathrm{~mm}, 0.630 \mathrm{~mm}$ respectively.

Figure 6 shows the total pressure loss coefficient for different cases. The blue line and red line represented the number of blades of 58 and 46 respectively. The number of blades is 58 ; the total pressure loss coefficient shows a linear growth trend with the tip clearance increasing. The slope of the blue line from zero tip clearance $(0.00 \% \mathrm{H})$ to small tip clearance $(0.80 \% \mathrm{H})$ is almost the same as from the small tip clearance $(0.80 \% \mathrm{H})$ to big tip clearance $(1.51 \% \mathrm{H})$. When the number of blades is 46 , the slope of the pressure loss curve from zero clearance to small tip clearance $(0.80 \% \mathrm{H})$ is also similar as the high count number of blades, but it changes gently from the small tip clearance $(0.80 \% \mathrm{H})$ to big tip clearance $(1.51 \% \mathrm{H})$. It meant that the number of blades affected total pressure loss coefficient more than tip clearance at the small tip clearance zone and with the tip clearance increasing the effect of tip leakage flow changed bigger. It gave us enlightenment that more attention must be paid on blade loading.

Figure 7 and Figure 8 showed the tip leakage mass flow and efficiency for different cases. The horizontal axis was tip clearance dividing blade height and the vertical axis was tip leakage mass flow. It was shown that at same tip clearance level the tip leakage mass flow of all cases with 58 blades are less than cases with 46 blades.

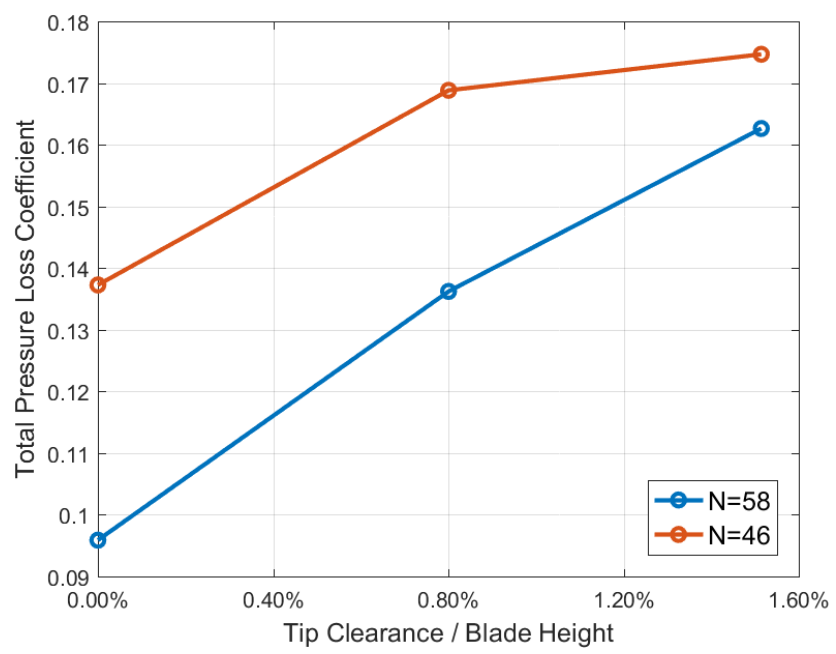

Figure 6. Total Pressure Loss Coefficients for Different Cases.

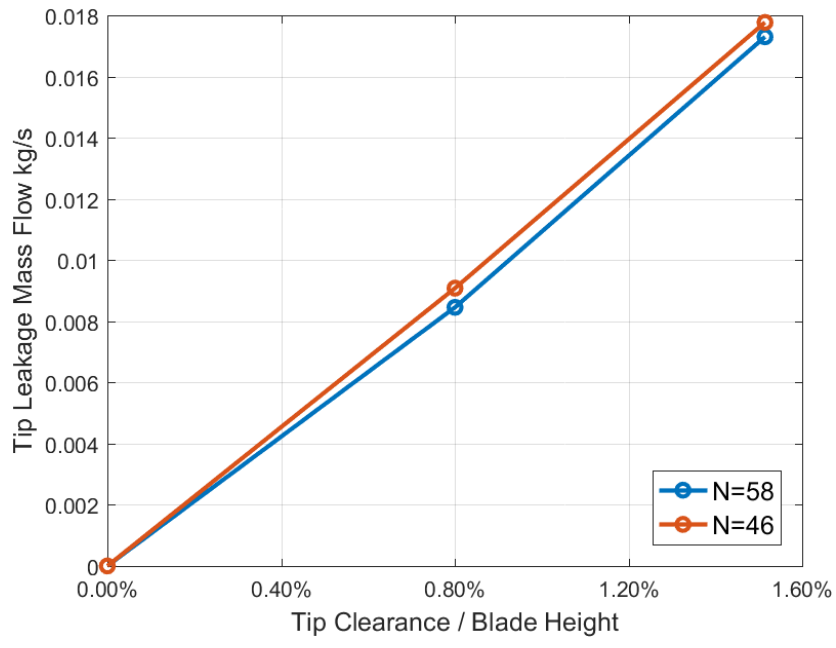

Figure 7. Tip Leakage Mass Flow for Different Cases. 


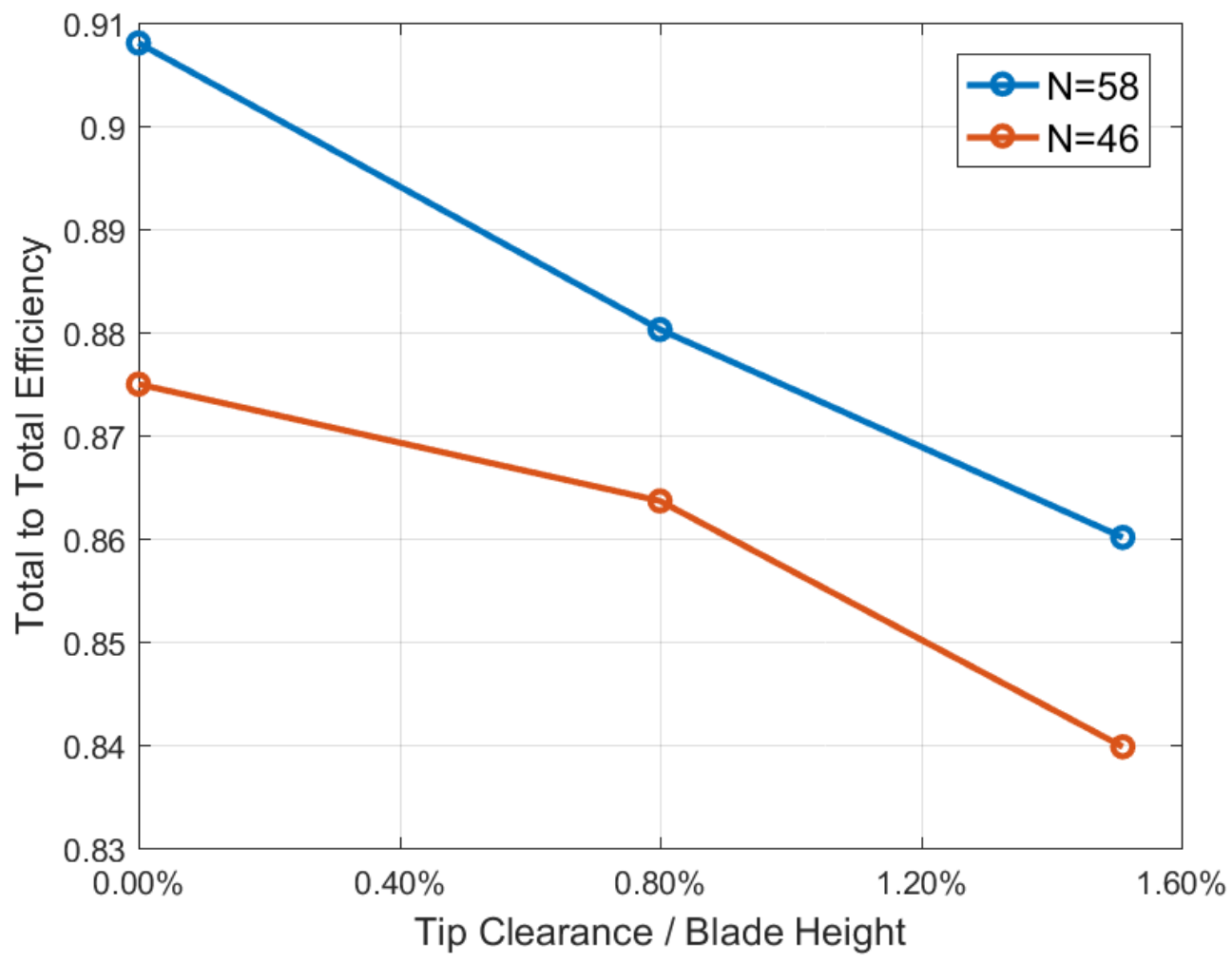

Figure 8. Total to total efficiency vs. tip clearance height.

Table 2. Different Shroud Tip Clearance and Number of Blades Setting and Model Results.

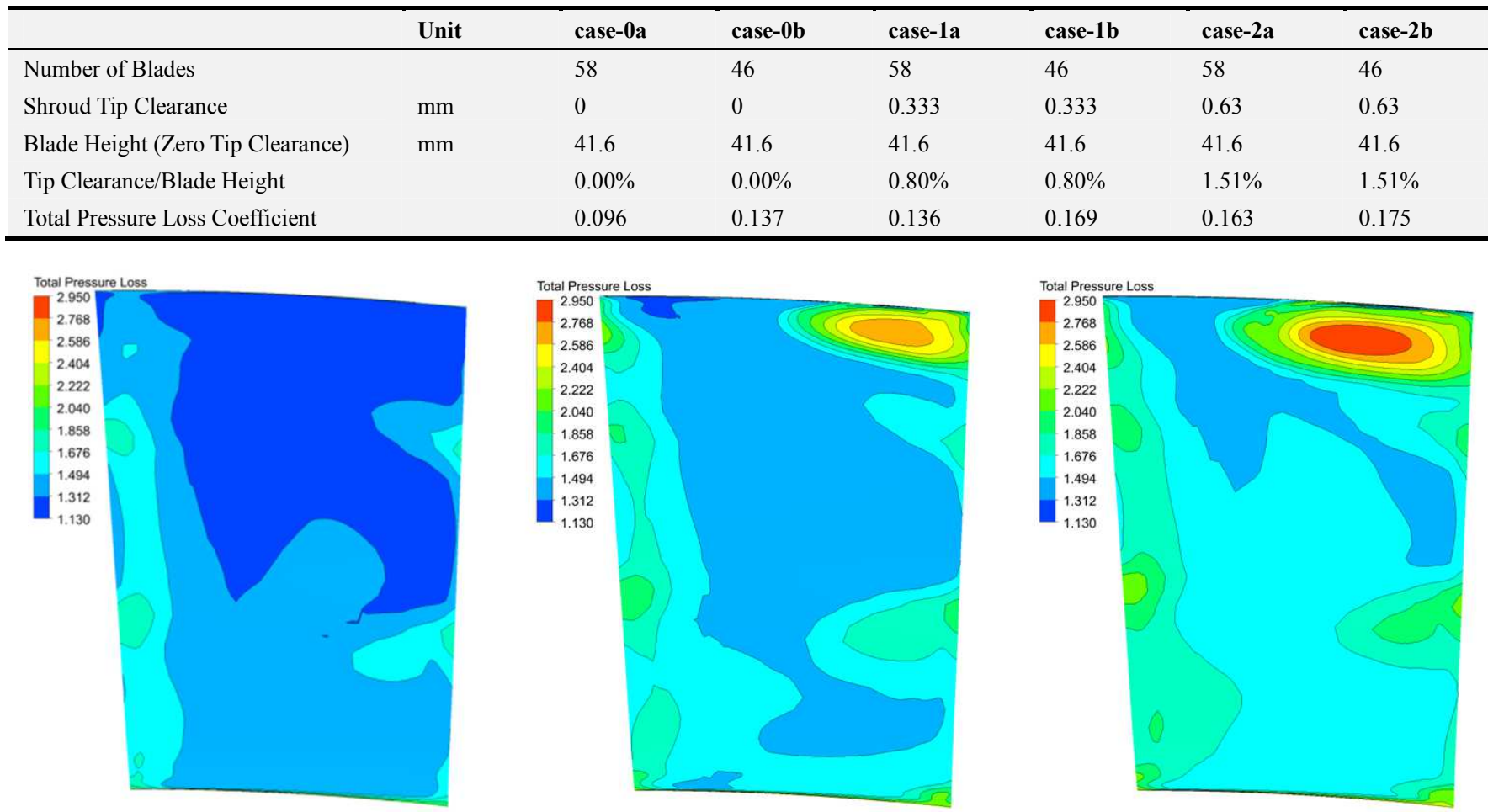

Figure 9. Rotor Outlet Plane Total Pressure Loss of Case $0 a(t / H=0.00 \%), 1 a(t / H=0.80 \%)$ and $2 a(t / H=1.51 \%)$. 

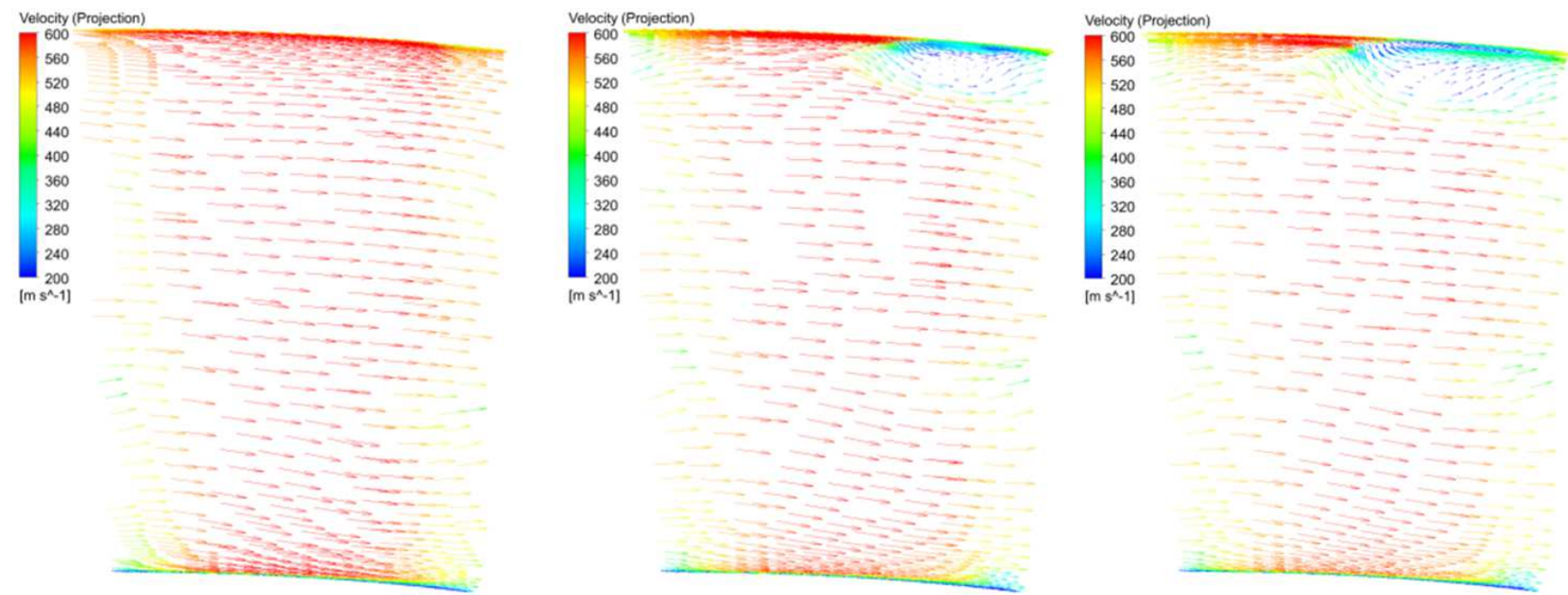

Figure 10. Rotor Outlet Plane Velocity (tangential projection) Vector of Case $0 a(t / H=0.00 \%), 1 a(t / H=0.80 \%)$ and $2 a(t / H=1.51 \%)$.

Figure 9 and figure 10 show the rotor outlet plane total pressure loss and velocity vector of case $0 \mathrm{a}, 1 \mathrm{a}, 2 \mathrm{a}$. It clearly showed the appearance of the tip leakage vortex from zero tip clearance to small tip clearance and its enhancement from small tip clearance to big tip clearance.

Figure 11 showed the passage static pressure distribution for case $1 \mathrm{a}$ and case $2 \mathrm{a}$ at three stream-wise locations. for case $2 \mathrm{a}$ which has big clearance, above the $50 \%$ span near the pressure side zone, the static pressure is lower the that in case1a. It mean than the existence of the clearance reduces the blade load.

Figure 12 shows Streamline contour of case 1a and $2 \mathrm{a}$ above $0.9 \mathrm{H}$. the total number of Streamline for these two cases are same, but the streamline flow passes the tip clearance for case $2 \mathrm{a}$ is much more than that for case $1 \mathrm{a}$, it shows that the leakage flow increase with the increase of the gap.

Figure 13 showed the blade loading chart of case $0 \mathrm{a}, 1 \mathrm{a}$ and $2 \mathrm{a}$ at $0.5 \mathrm{H}, 0.98 \mathrm{H}$. It shows that when the clearance increased both of the $0.50 \mathrm{H}$ and $0.98 \mathrm{H}$ blade loading changes were obvious. The exit clearance decreased the blade surface pressure at $0.50 \mathrm{H}$; it mainly affects the front part of the blade. But at $0.98 \mathrm{H}$ the suction side pressure at the back part of the blade is also lower than that in the zero clearance.
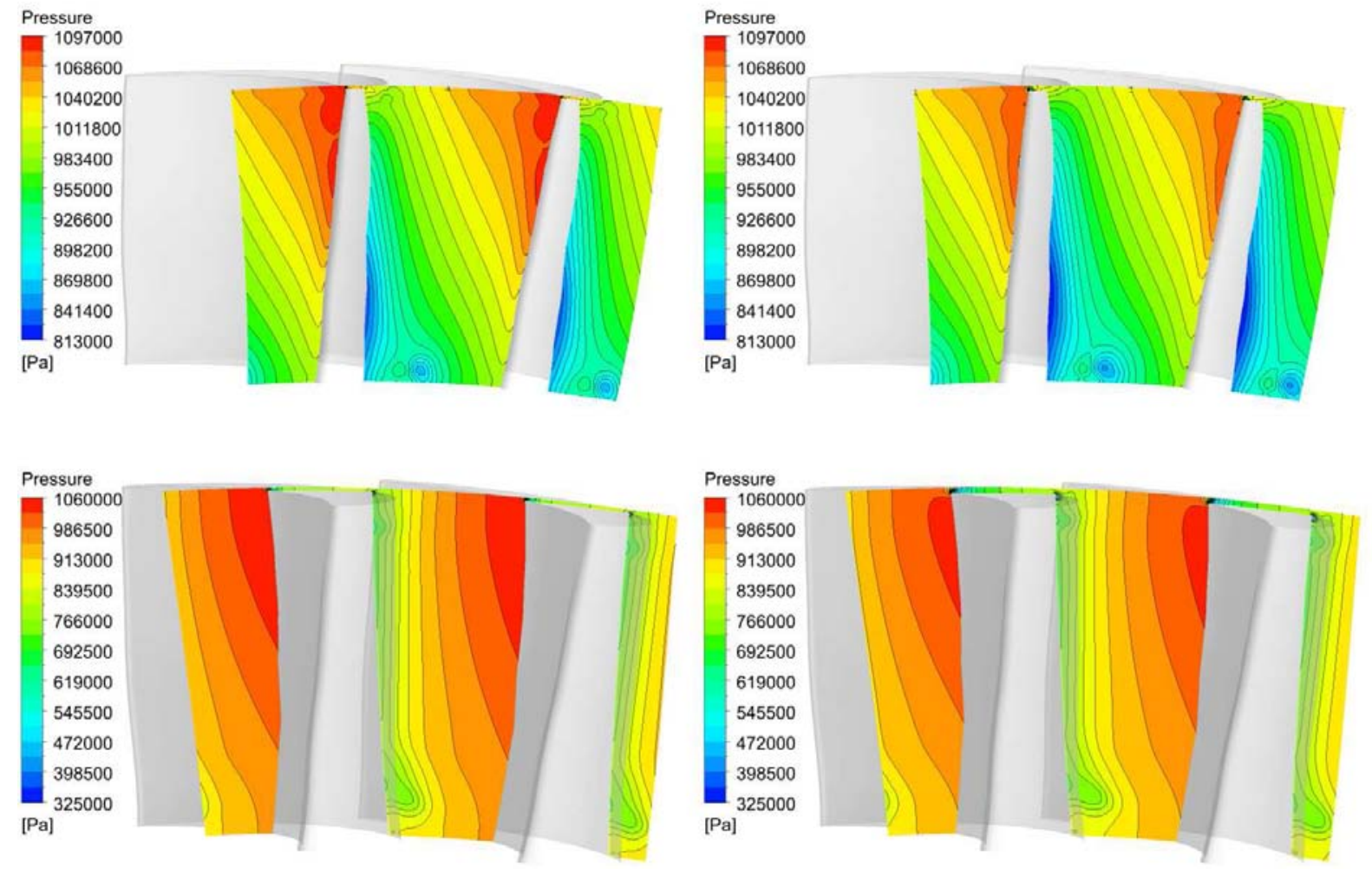

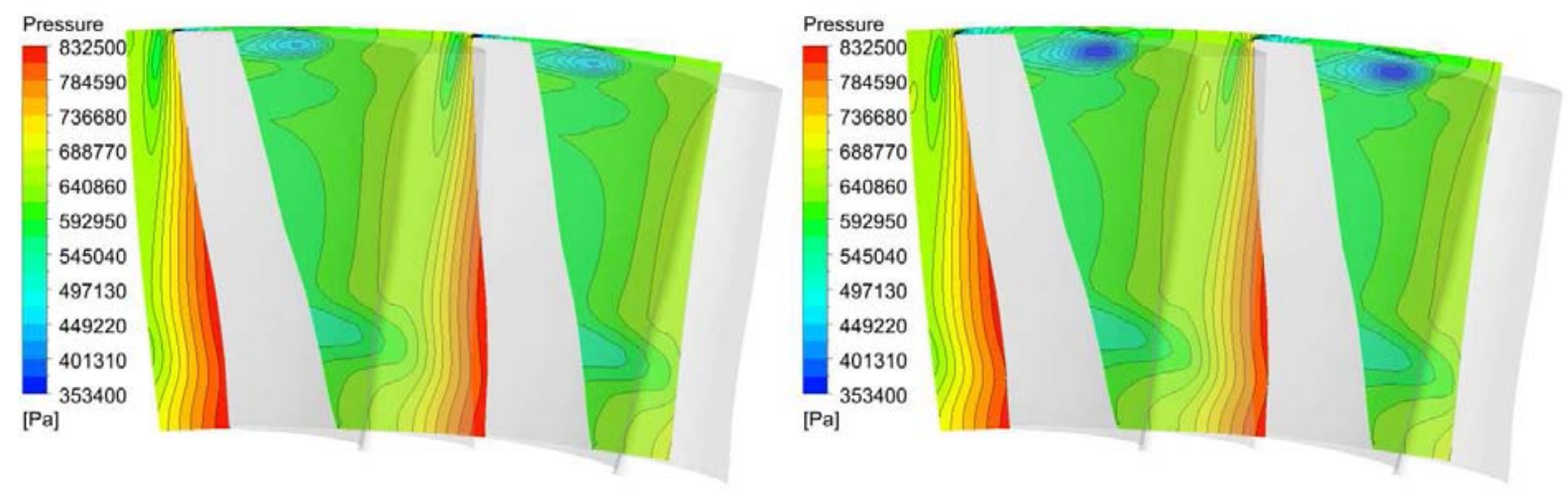

Figure 11. Blade-to-Blade Pressure contour of case $1 \mathrm{a}(\mathrm{t} / \mathrm{H}=0.80 \%)$ at $0.996 \mathrm{H}$ and $2 \mathrm{a}(\mathrm{t} / \mathrm{H}=1.51 \%)$ at $0.9925 \mathrm{H}$.

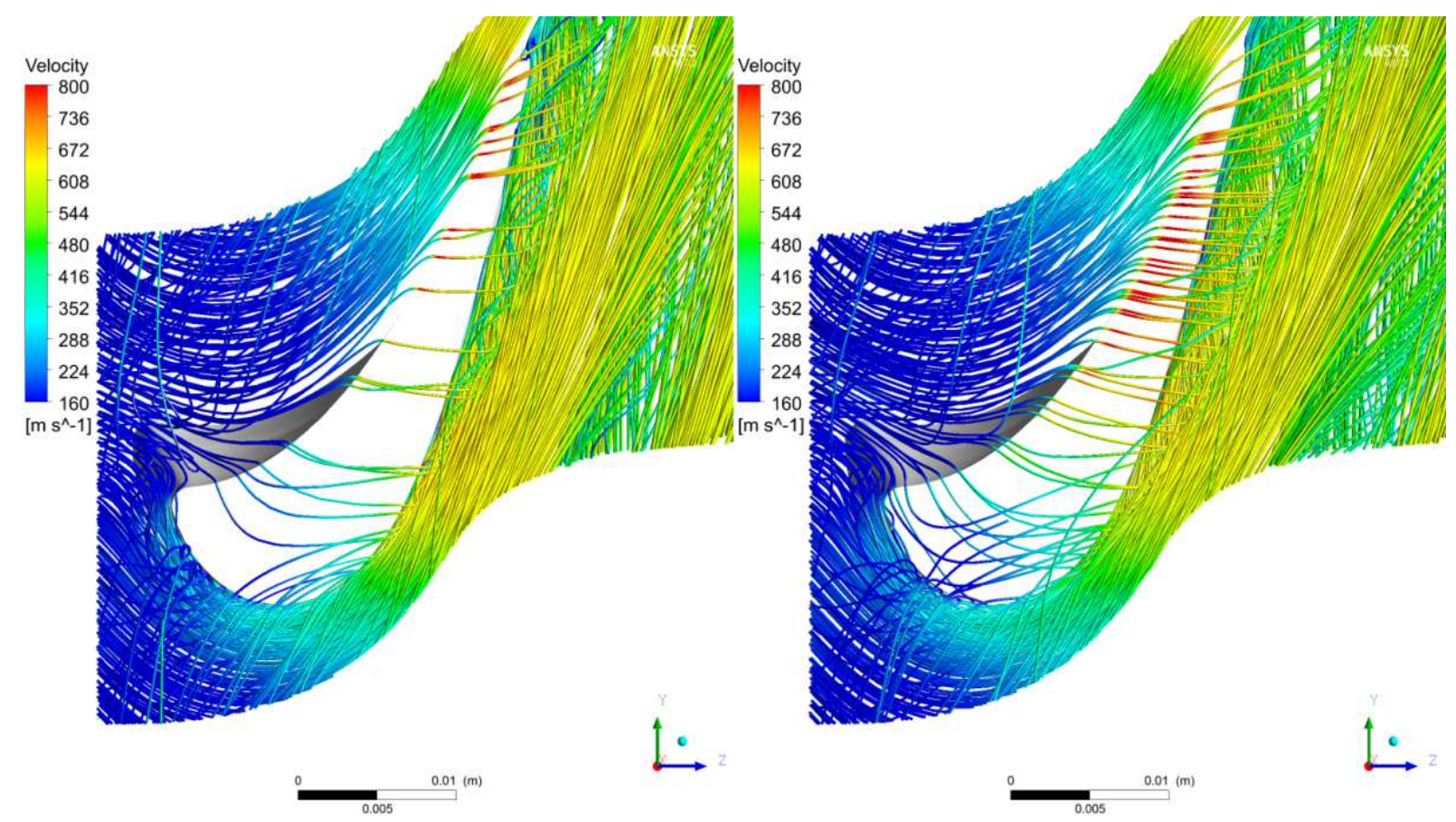

Figure 12. Streamline contour of case $1 \mathrm{la}$ and $2 \mathrm{a}$ above $0.9 \mathrm{H}$.
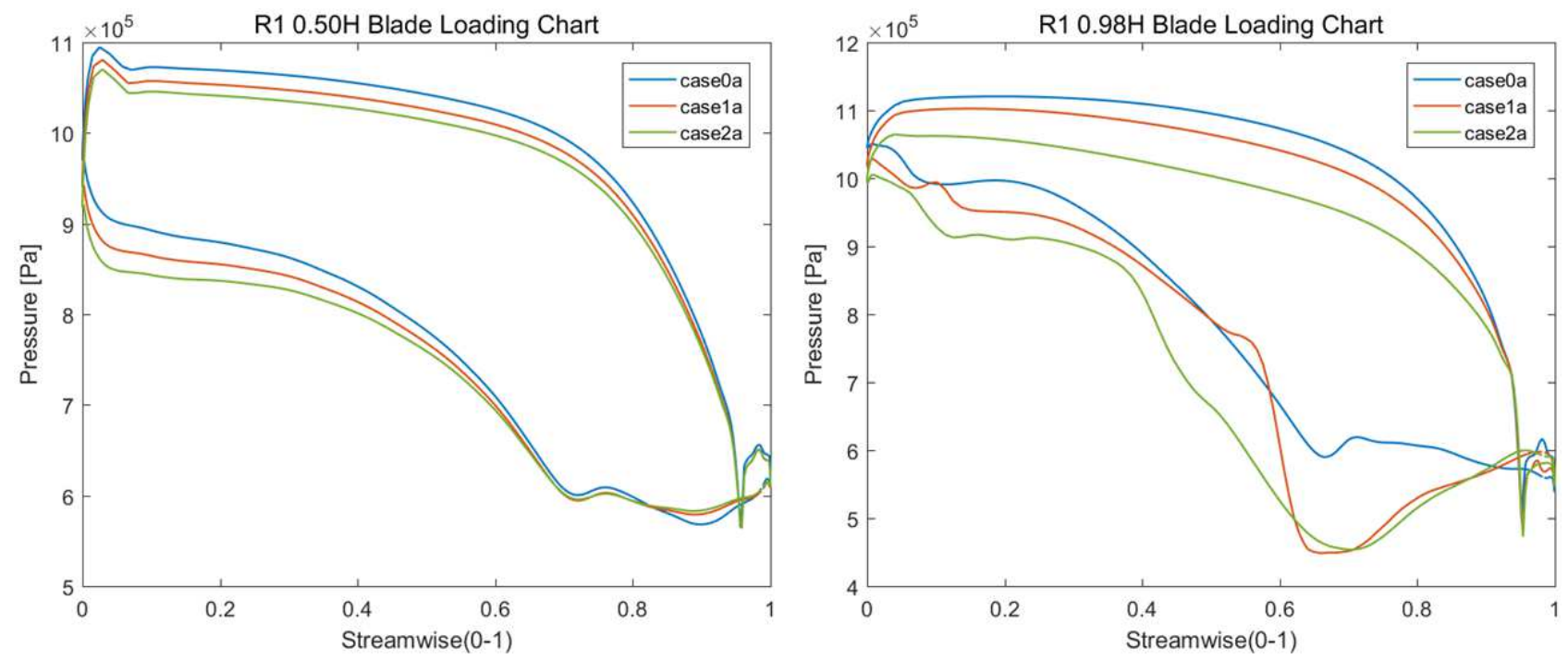

Figure 13. Blade Loading Charts of Case $0 a$, Ia and $2 a$ at $0.50 H, 0.98 H$. 


\subsection{The Effect of Blade Loading on Tip Clearance}

From weight and cost consideration it is advantageous to minimize the number of rotor blades in a turbine. However, without increasing the stage reaction this implies higher blade loading, for the same axial chord and possible performance. In order to investigate how the blade loading effect on the tip clearance flow. Three cases with fewer blades were conducted.

Figures 14, 15 and 16 show the rotor outlet plane total pressure loss of cases for zero tip clearance, small tip clearance and big tip clearance respectively. They showed that the total pressure loss increased with the decrease of blades numbers for all cases. The loss contour showed that the secondary flow was stronger for small blade numbers. This was because for the small blade numbers the flow control capacity became worse than that of the larger blade numbers. The secondary vortex was easy to develop in the blade channel.

Figures 17 and 18 showed the streamline starting from the

Total Pressure L
\begin{tabular}{|l}
3.046 \\
2.855 \\
2.663 \\
2.471 \\
2.280 \\
2.088 \\
1.896 \\
1.705 \\
1.513 \\
1.322 \\
1.130
\end{tabular}

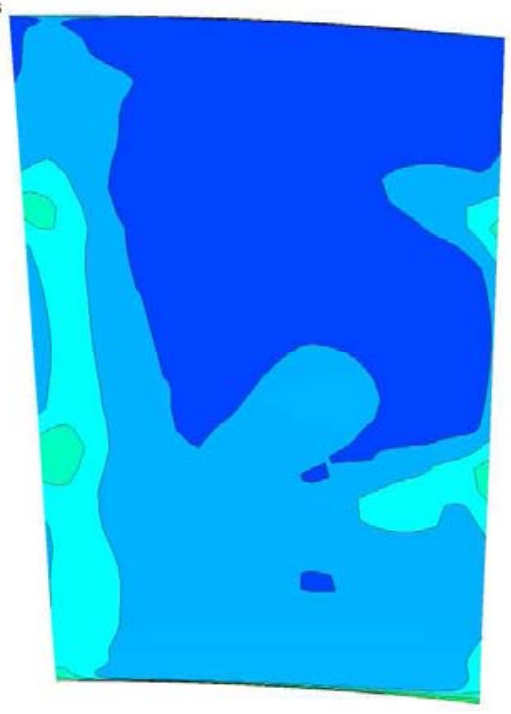

Figure 14. Rotor Outlet Plane Total Pressure Loss of Case $0 a(N=58)$ and $0 b(N=46)$.
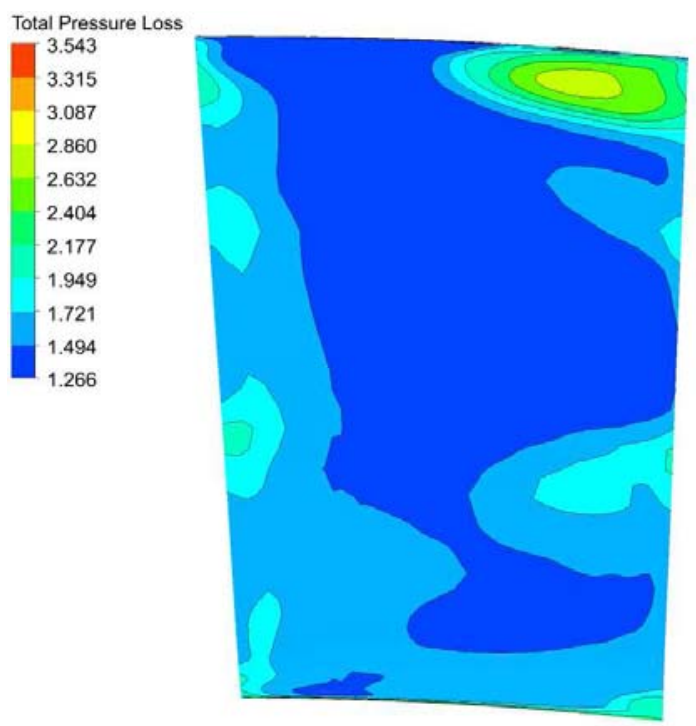

Figure 15. Rotor Outlet Plane Total Pressure Loss of Case 1 a $(N=58)$ and $1 b(N=46)$.

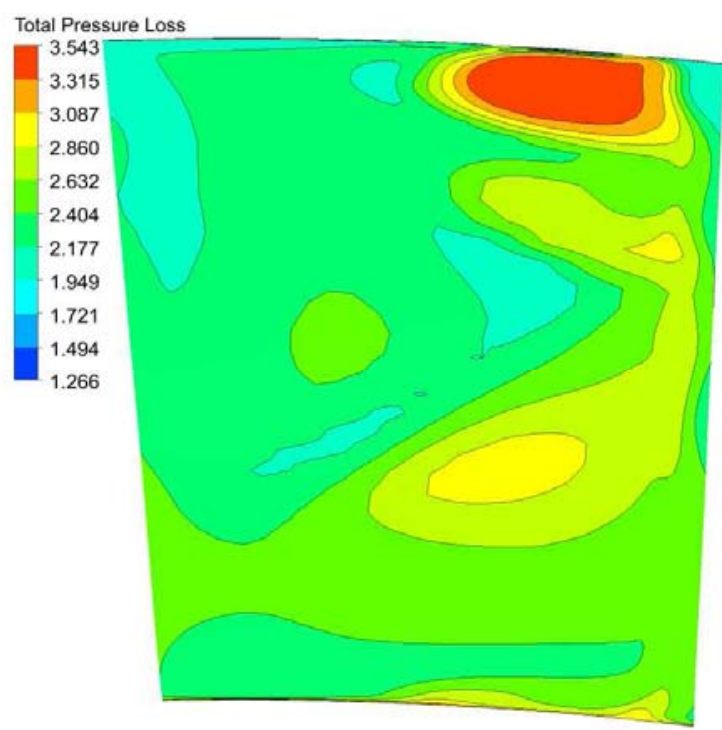

rotor tip clearance to flow to downstream. The tip leakage flow vortex formed from two flows. One came from the zone located at the leading edge to about $10 \%$ to $20 \%$ axial chord length, the other came from the left zone of the blade, the two leakage flow vortices moved backward if the number of the blades decreased from 58 to 46 . This demonstrated that the higher blade numbers with less blade loading had fewer losses.

Figure 19 showed velocity contours located at $7 \%, 11 \%$, $30 \%$ axial chord length respectively. It is shown that the less blade counts with higher blade loading had higher levels of secondary flow velocity. Figure 20 demonstrated that the higher loading case $1 \mathrm{~b}$ also had higher entropy and higher losses. Figures 21 and 22 were the velocity contours and entropy for larger clearance cases. The results are similar to the low tip clearances shown in Figures 19 and 20. It was worth mentioning that the tip leakage flow mixing with the main flow earlier at the small blade number.

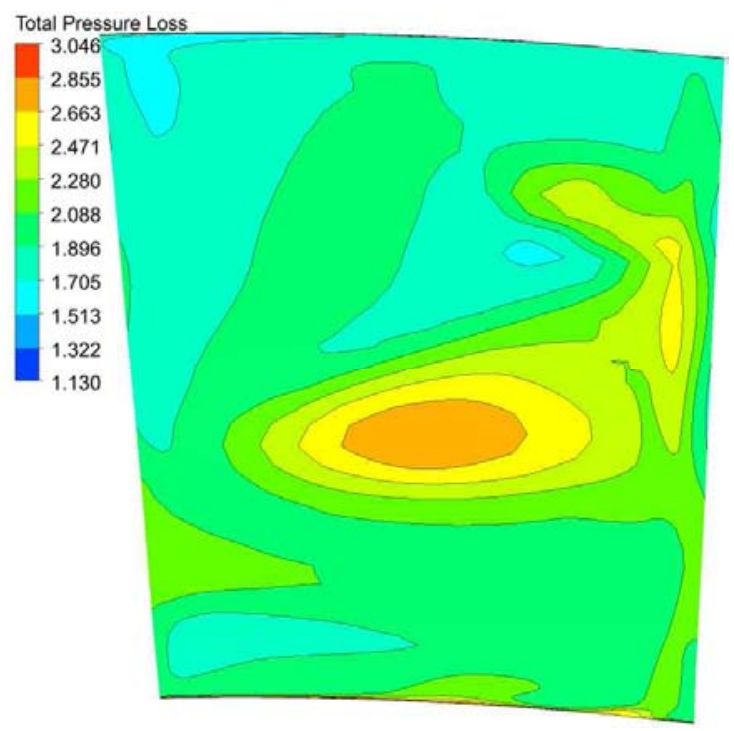

Total Pressure Loss

Figure 15. Rotor Outet Plane Total Pressure Loss of Case la $(N=58)$ and 1 b (N=46). 

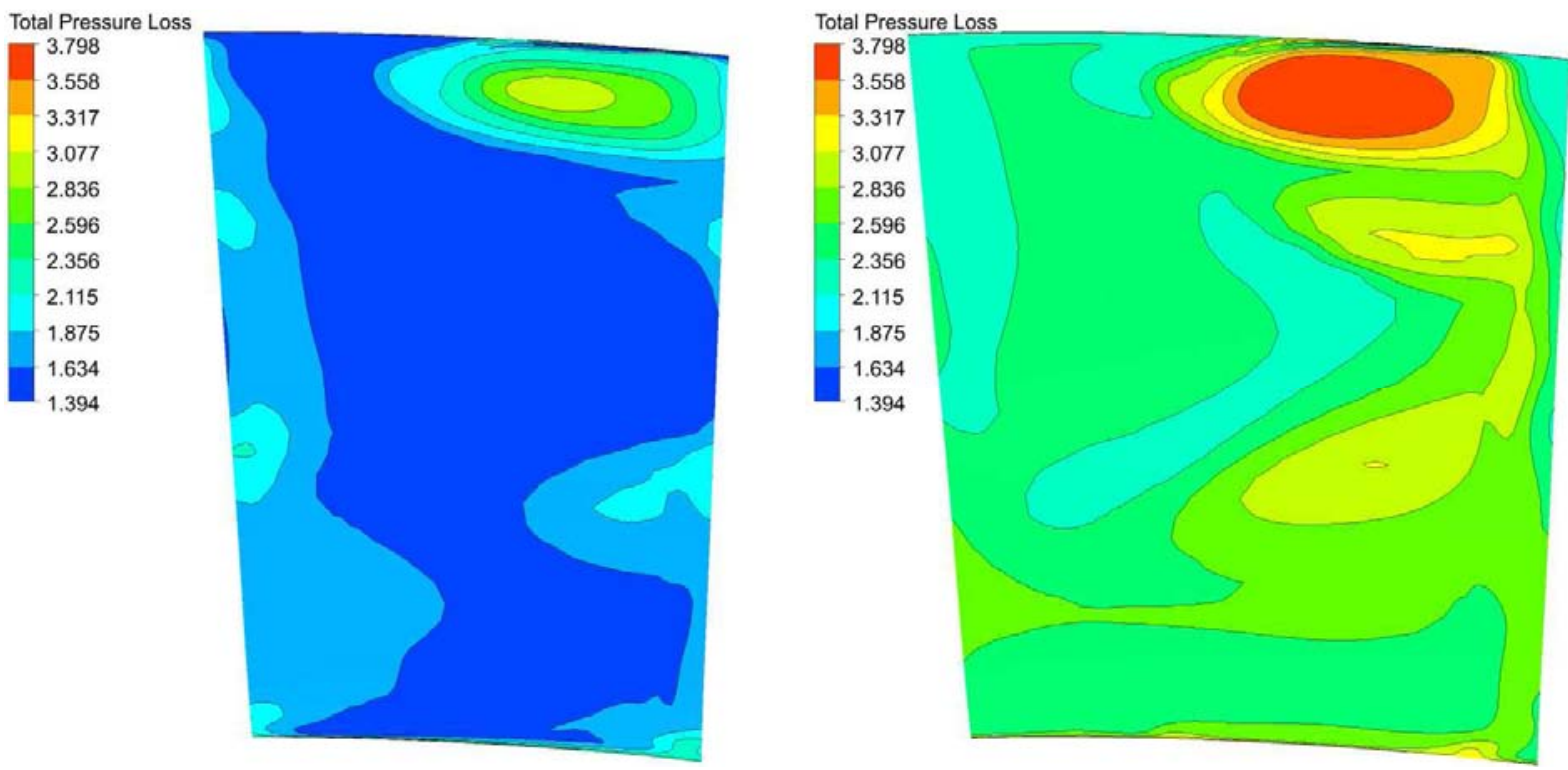

Figure 16. Rotor Outlet Plane Total Pressure Loss of Case $2 a(N=58)$ and $2 b(N=46)$.
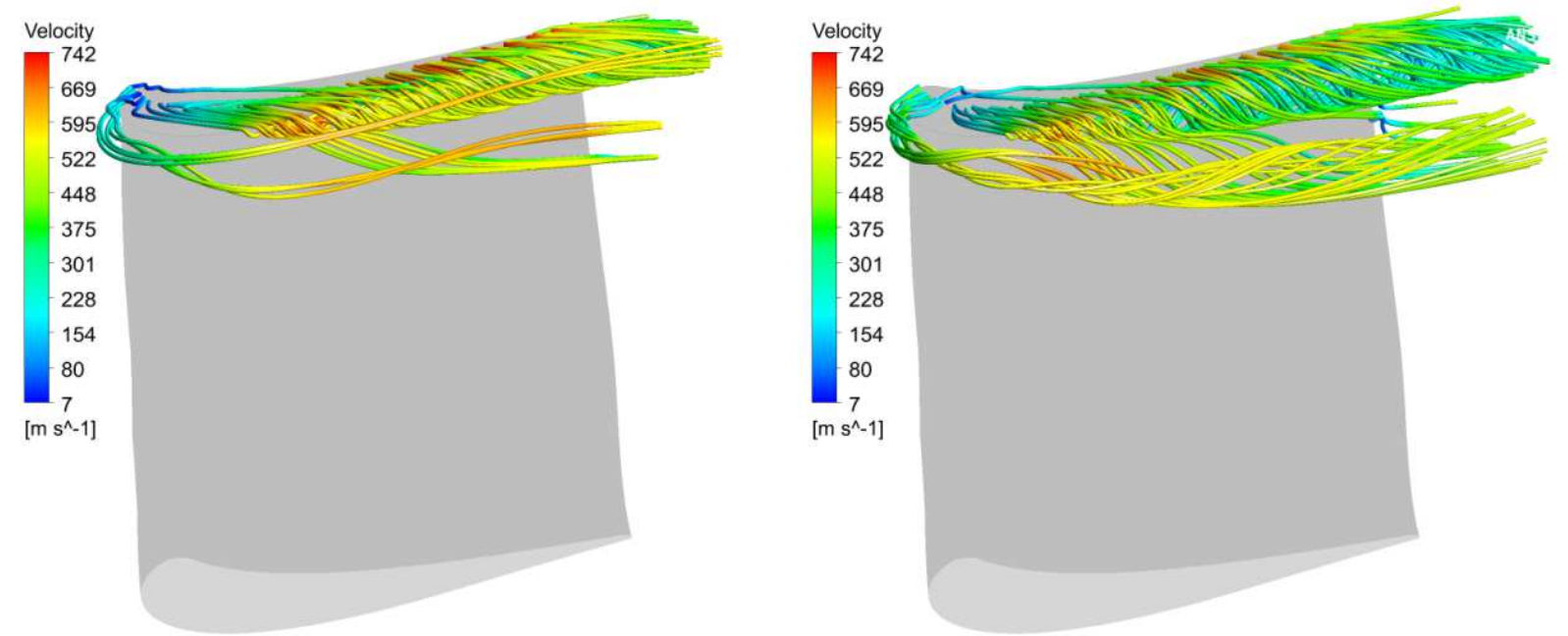

Figure 17. Streamline from rotor tip clearance of case $1 a(N=58)$ and $1 b(N=46)$.
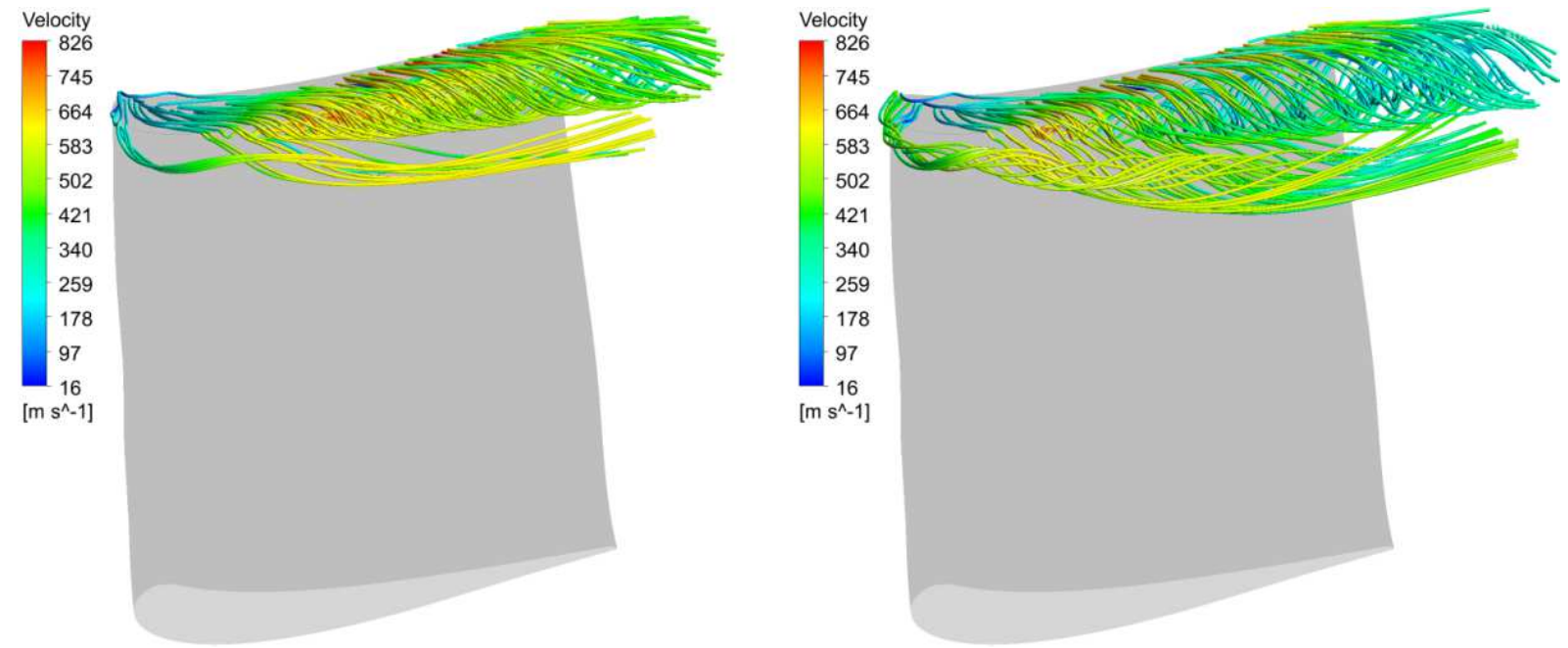

Figure 18. Streamline from rotor tip clearance of case $2 a(N=58)$ and $2 b(N=46)$. 


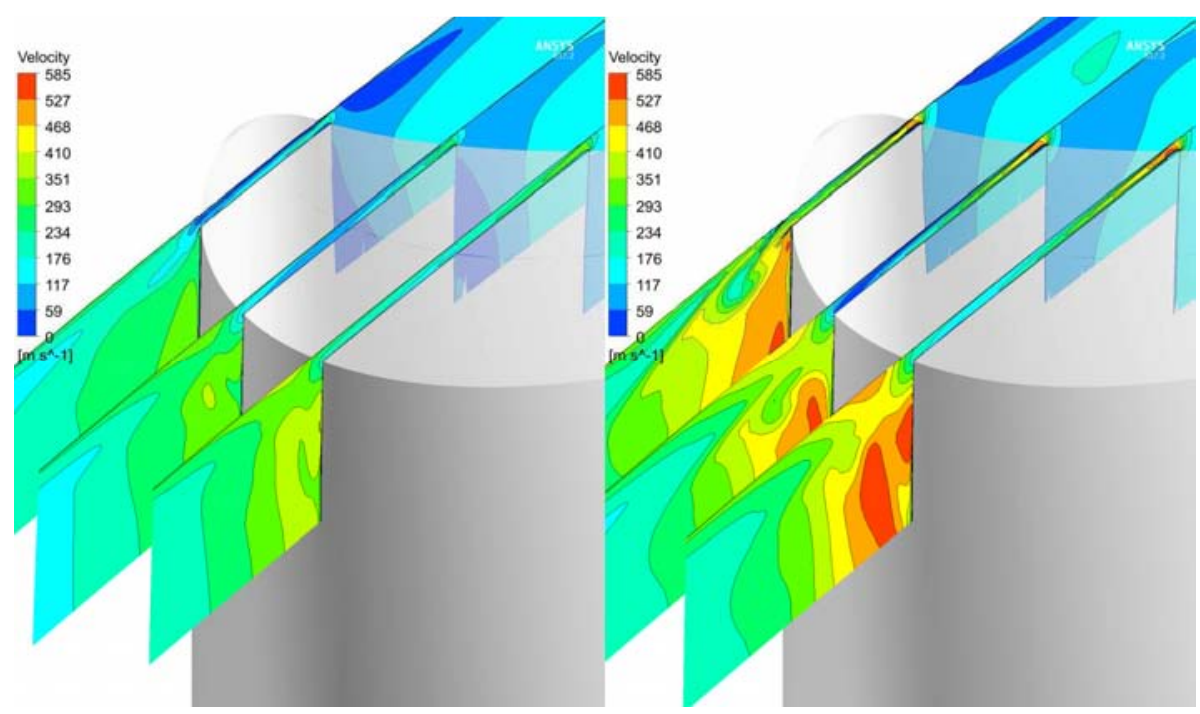

Figure 19. Velocity contours of case $1 a(N=58)$ and $1 b(N=46)$.

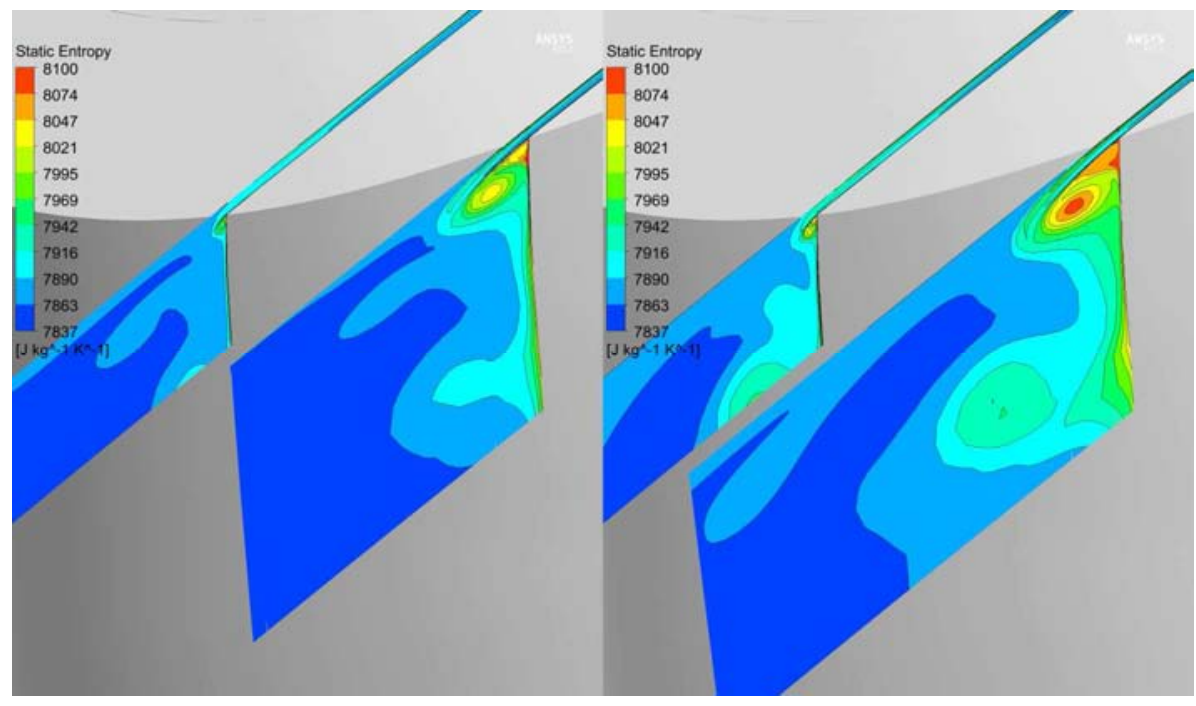

Figure 20. Static entropy contour slice at $57 \%$ and $70 \%$ axial chord length of case 1 a $(N=58), 1 b(N=46)$

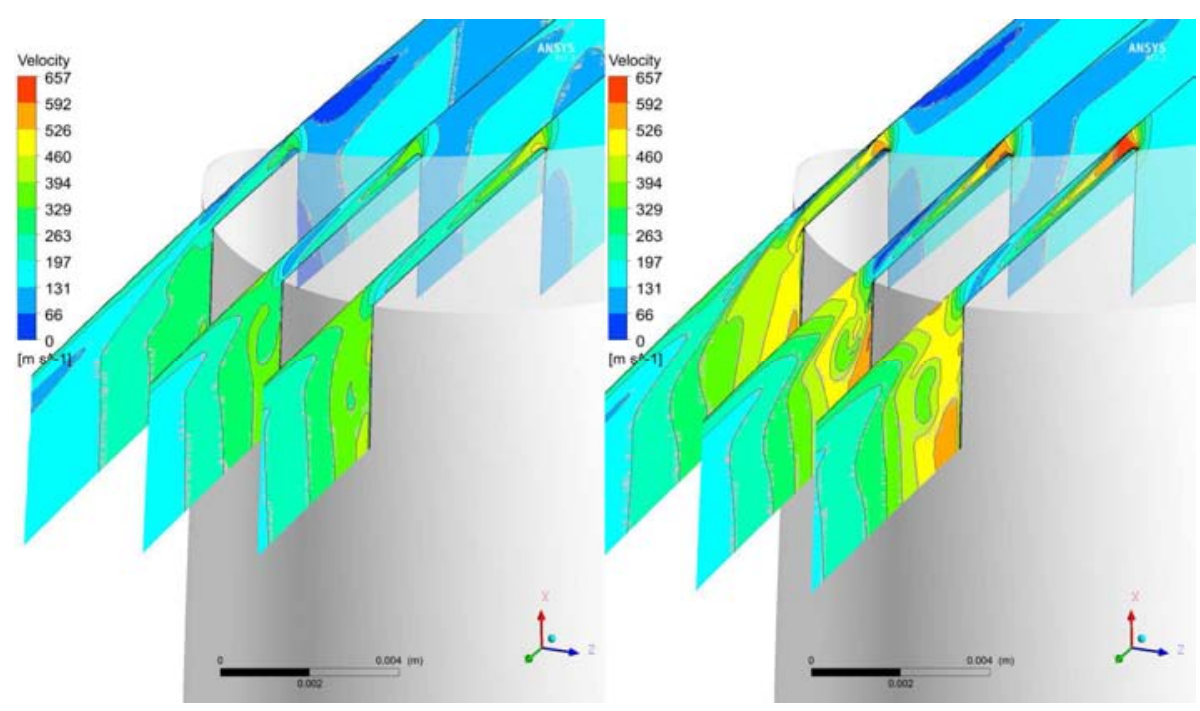

Figure 21. Velocity contour slice of case $2 a(N=58)$ and $2 b(N=46)$. 

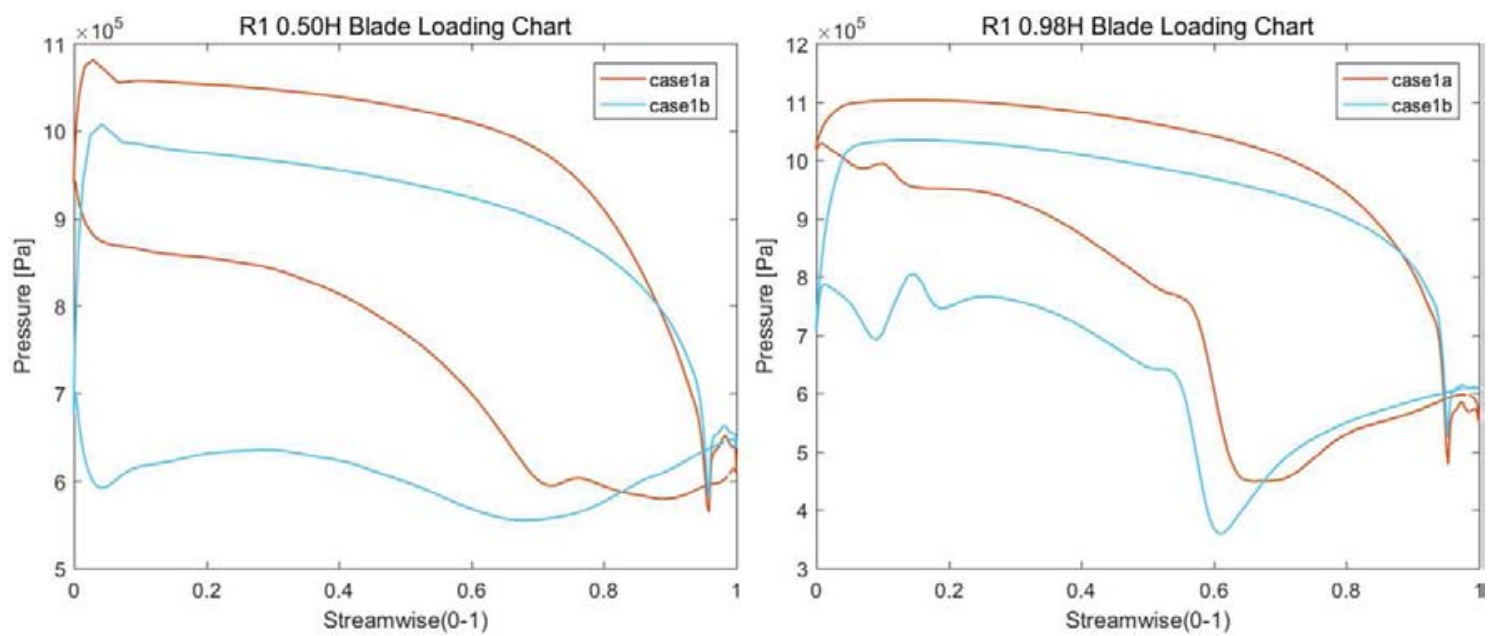

Figure 22. Blade Loading Charts of Case $1 \mathrm{a}$ and $1 \mathrm{~b}$ at $0.50 \mathrm{H}, 0.98 \mathrm{H}$
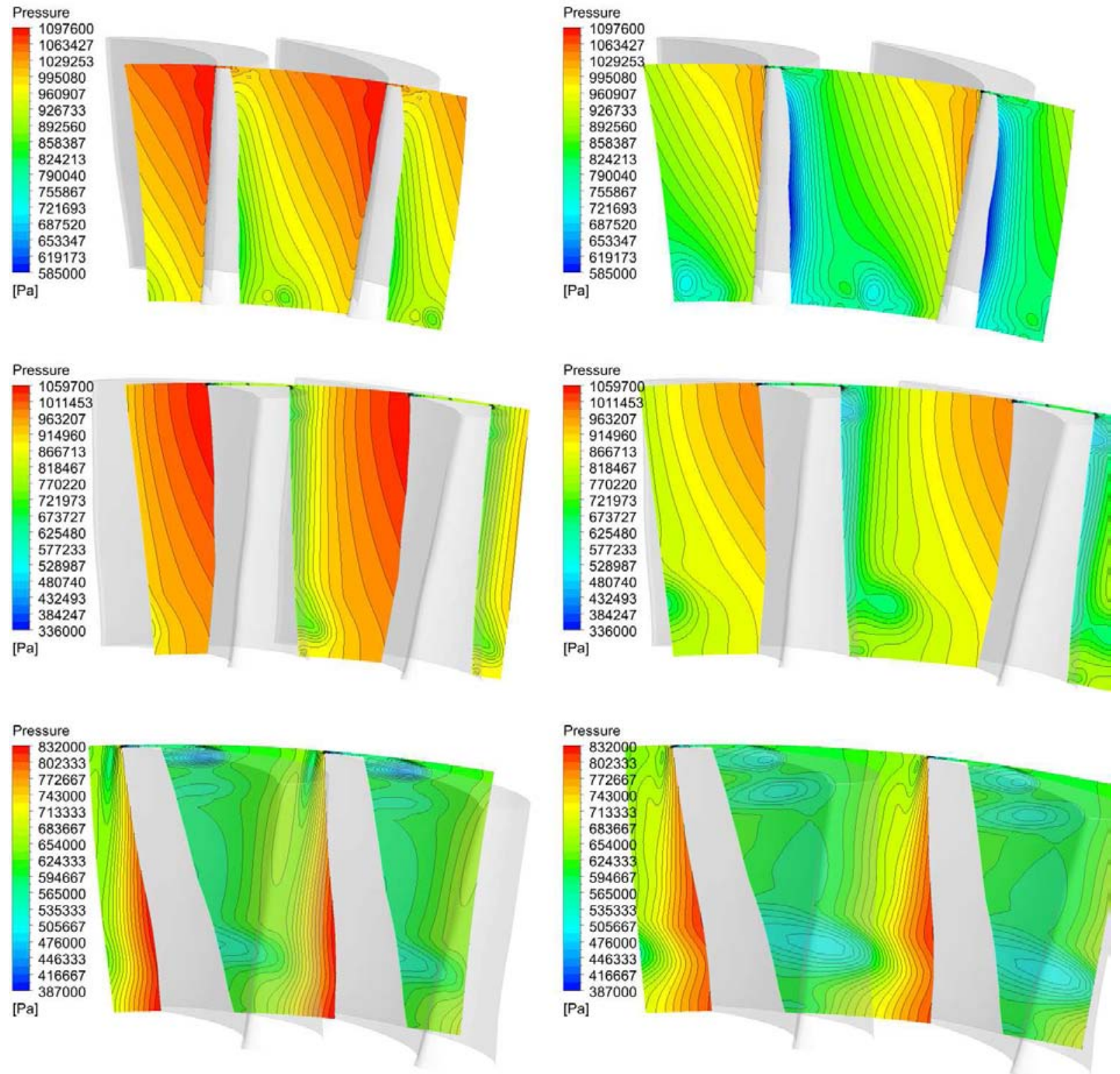

Figure 23. Passage Pressure contour of case $1 a(N=58)$ and $1 b(N=46)$ at stream-wise location 1.07,1.22,1.32. 


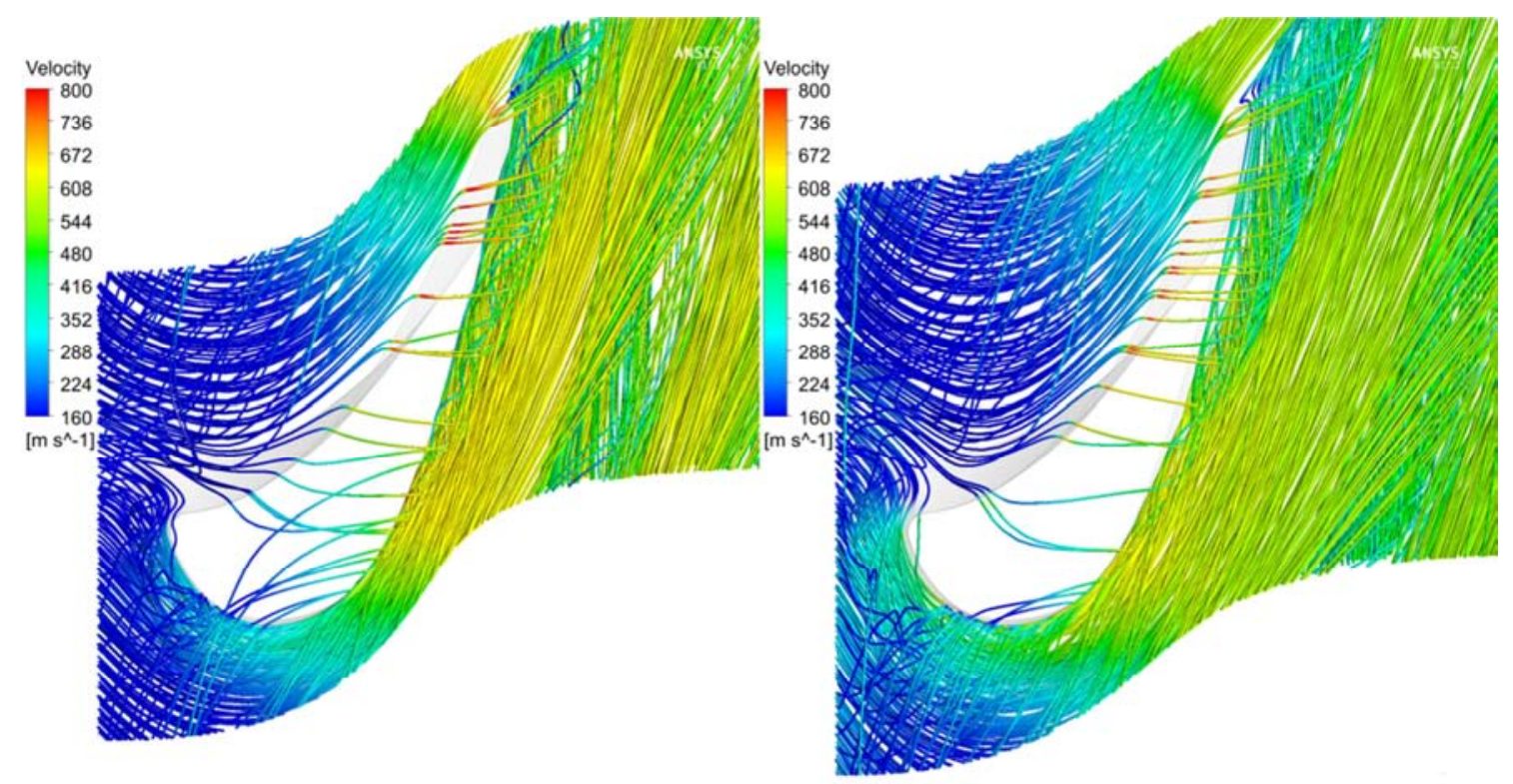

Figure 24. Streamline contour of case 1 a $(N=58)$ and $1 b(N=46)$ above $0.9 H$.

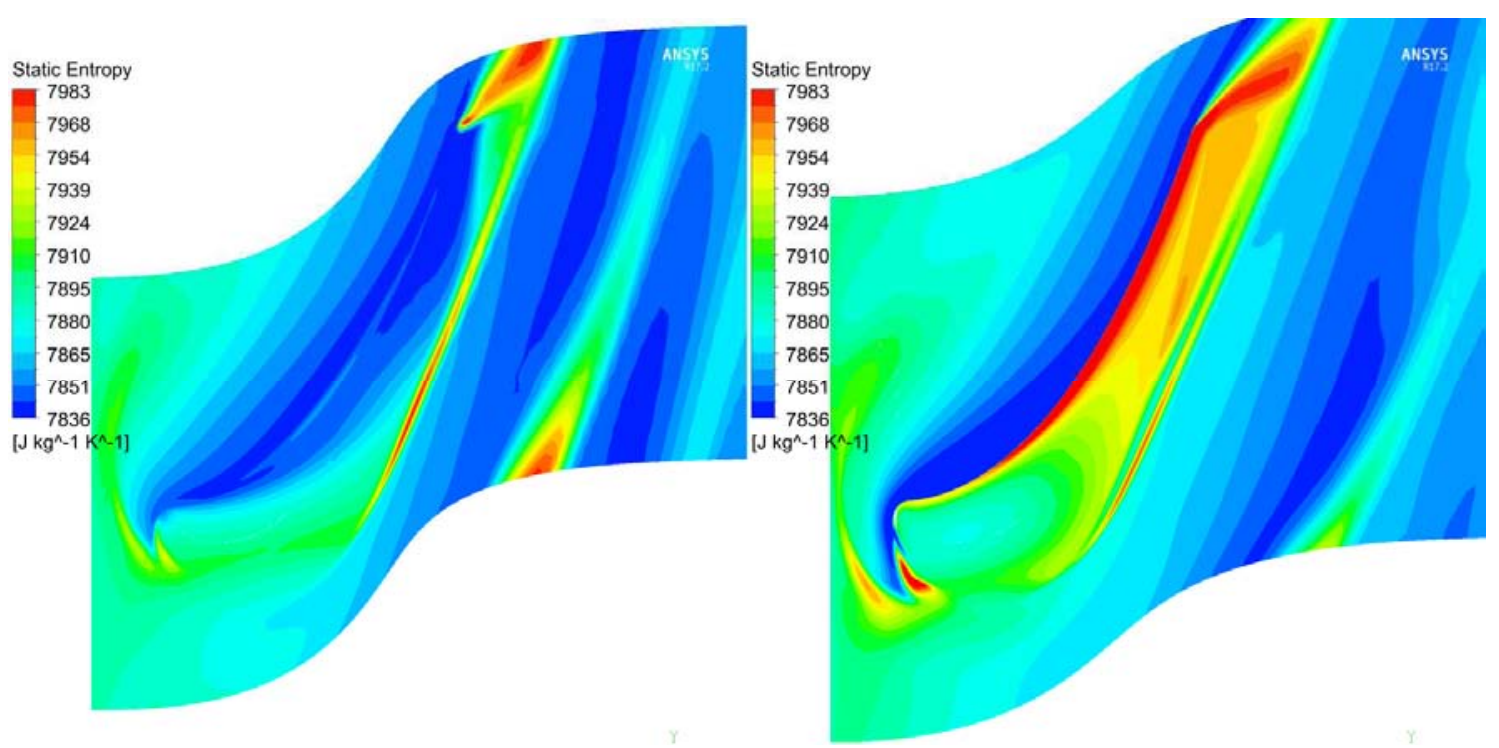

Figure 25. Static Entropy contour of casela at 0.0.996H and caselb at 0.0.9925H.

Figure 22 is the blade loading comparisons at different loadings at different blade heights. It was shown that even though the blade geometry was the same for both cases, the tip clearance and number of blades impacted the blade loading distributions. It could be seen that at the tip range, the blade loading changed bigger. At mid-span, the blade loading changed smaller. This demonstrated that the blade loading and tip clearance combined influences were bigger than the sum of their individual impacts. This was agreed with early study [18] that the secondary flow of the turbine blade was also impacted by pitch-width ratio, i.e. blade loading.

\section{Conclusions}

In the study, it demonstrated that the tip clearance losses not only impacted by the level of the clearances, but also impacted by the blade loading. The study results agreed with the previous research [18] that the pitch-width ratio, i.e. blade count had an optimal value. However, this study further pointed out the optimal pitch-width ratio or blade counts were also related to tip clearances. The turbine designers should try to optimize the blade loading design for tip clearance and secondary flow. In the case of a reasonable number of blades, the effect of clearance on the total pressure loss and efficiency had a linear relationship. When the clearance increased, the strength of the clearance vortex increased and the blade loading at the tip of the blade was strongly impacted by tip clearance level. Under high load (small number of blades), the effect of clearance on the total pressure loss and efficiency is no longer linear. When the clearance increased, the leakage flow and the strength of the clearance vortex increased and the blade loading at the tip of the blade was strongly impacted by tip clearance level. Under 
high load (small number of blades), the effect of clearance on the total pressure loss and efficiency is no longer linear. because the secondary flow loss increases significantly when the number of blades is small, which can be seen from the blade passage static pressure distribution at the three streamwise location in figure 23. figure 24 shows the streamline contour of casela and $1 \mathrm{~b}$. they have the same level tip clearance but different blade loading. it shows that the tip clearance leakage flow was effected by the blade loading. In case $1 \mathrm{~b}$ with the high blade loading, the streamline is denser in the back part of the blade. this can also be seen from figure 25 the static entropy distribution on the middle cross section of the tip clearance. under high load the entropy increase of gap flow is greater.

\section{References}

[1] Futral, SM, Holeski, DE. Effect of rotor tip clearance on the performance of a 5-inch single stage axial flow turbine (TMX1757). Washington, DC: NASA, 1969.

[2] R. E. Peacock, A review of turbomachinery tip gap effects: Part 2: Rotating machinery, International Journal of Heat \& Fluid Flow, 1986, vol. 4, pp. 3-16.

[3] J. Moore, J. G. Moore, G. S. Henry, U. Chaudhry, Flow and heat transfer in turbine tip gaps, Journal of Turbomachinery, 111 (1989) 301-309.

[4] P. J. Newton, G. D. Lock, S. K. Krishnababu, H. P. Hodson, W. N. Dawes, J. Hannis, C. Whitney, Heat transfer and Aerodynamics of turbine blade tips in a linear cascade, Journal of Turbomachinery 128 (2006) 300-309.

[5] C. Bringhenti, J. R. Barbosa, Effects of Turbine Tip Clearance on Gas Turbine Performance, GT2008-50196, pp. 1715-1721.

[6] C. Xu and R. S. Amano, An Implicit scheme for cascade flow and heat transfer analysis, ASME J. of Turbomachinery, April, 2000. https://doi.org/10.1115/1.555447.

[7] Kypuros, JA, Melcher, KJ. A reduced model for prediction of thermal and rotational effects on turbine tip clearance (NASA/TM-2003-212226). Washington, DC: NASA, 2003.
[8] C. Xu and R. S. Amano, A hybrid numerical procedure for cascade flow analysis, Numerical Heat Transfer, Vol., 37, No. $2 . \quad$ p. 141-164, March, 2000. https://doi.org/10.1080/104077900275468.

[9] S. W. Lee, H. S. Moon, S. E. Lee, Tip gap height effects on flow structure and heat/mass transfer over plane tip of a highturning turbine rotor blade, International Journal of Heat and Fluid Flow 30 (2009) 198-210.

[10] G. S. Azad, J. Han, S. Teng, R. J. Boyle, Heat transfer and pressure distributions on a gas turbine blade tip, Journal of Turbomachinery 122 (2000) 717-724.

[11] G. S. Azad, J. Han, R. J. Boyle, Heat transfer and flow on the squealer tip of a gas turbine blade, Journal of Turbomachinery 122 (2000) 725-732.

[12] C. Xu and R. S. Amano, Flux-splitting finite volume method for turbine and heat transfer analysis, Computational Mechanics, April, 2001. https://link.springer.com/article/10.1007/s004660000219.

[13] D. Yongle S. Baowei and W. Peng, Numerical investigation of tip clearance effects on the performance of ducted propeller, International Journal of Naval Architecture and Ocean Engineering, Volume 7, Issue 5, September 2015, Pages 795804.

[14] Booth T., Importance of tip clearance flows in turbine design, VKI lecture series, 1985-05: tip clearance effects in axial turbomachines, Von Karman Institute for Fluid Dynamics., Belgium (1985).

[15] Yaras and Sjolander, M. Yaras, Sjolander S., Effects of simulated rotation on tip leakage in a planar cascade of turbine blades: part I-tip gap flow, Journal of turbomachinery, 114 (3) (1992), pp. 652-659.

[16] You D., Wang M., P. Moin, Mittal R., Effects of tip-gap size on the tip-leakage flow in a turbomachinery cascade, Physics of Fluids (1994-present), 18 (2006), p. 105102.

[17] V. Shyam, A. Ameri, J.-P. Chen, Analysis of unsteady tip and endwall heat transfer in a highly loaded transonic, turbine stage, Tech. Rep. TM-2010-216740, NASA (2010).

[18] C. Xu and R. S. Amano, Computational Analysis of PitchWidth Effects on the Secondary Flows of Turbine Blades, Computational Mechanics, Vol. 34, No. 2, pp. 111-120, 2004. 